\title{
Interaction of the Electrical Conductivity of Recycled Pulp Colloidal Suspension with Chitosan and Bentonite as a Papermaking Additive System
}

\begin{abstract}
Ali Askar Taheri, Mehdi Rahmaninia,* and Amir Khosravani
The performance of chitosan biopolymer-bentonite microparticle system in recycled pulp colloidal suspension of old corrugated containers with different electrical conductivities was considered. Various instrumental analyses (atomic force microscopy, field emission scanning electron microscopy, dynamic light scattering, and Fourier-transform infrared spectroscopy) were applied to characterize the applied chemicals. The results indicated that the mentioned system could increase the process and mechanical properties in comparison to the control sample. Although increasing the electrical conductivity of the recycled pulp decreased the performance of chitosan-bentonite system to some extent, the system was successful in its mission even at the highest electrical conductivity, i.e., increasing the retention, drainage, tensile index, tear index, bending strength and internal bonding strength, with improvement of approximately $41 \%, 32 \%, 8 \%, 16 \%, 26 \%$, and $57 \%$ in comparison with the control samples, respectively. Therefore, this method can be a fascinating approach to the papermaking process. Moreover, the probable reasons of the mentioned achievements were considered and discussed.
\end{abstract}

DOI: 10.15376/biores.17.1.1805-1817

Keywords: Electrical conductivity; Chitosan biopolymer; Bentonite; Process properties; Recycled Pulp suspension

Contact information: Wood and Paper Science \& Technology Department, Faculty of Natural Resources, Tarbiat Modares University, Iran; *Corresponding author: rahmaninia@modares.ac.ir;

https://orcid.org/0000-0001-6943-0146

\section{INTRODUCTION}

Various types of recycled fibers have considerable contribution in terms of providing raw fibrous material for the paper industry (Sabazoodkhiz et al. 2017). Economic issues, environmental concerns, and the importance of sustainable development are the driving forces of this positive trend (Arminen et al. 2013). Recent developments in papermaking technologies, e.g., higher machine speeds, alongside new demands in process and product qualities, e.g., drainage, retention, mechanical properties, etc., has resulted in attention to chemical additives, especially micro/nanoparticle systems (Rahmaninia and Khosravani 2015). However, the performance of chemical additives can be affected by different technical variables in the paper industry (Perng et al. 2013). In this respect, since the primary part of the papermaking process is performed in aqueous media with different dissolved and colloidal substances, the electrical conductivity of pulp suspension is an important factor, particularly in paper recycling mills (Hubbe 2000; Bourassa et al. 2003; Pruszynski and Jakubowski 2002; Ordóñez et al. 2009; Lindqvist 2013). This factor, in fact, is an indicator of the total dissolved and colloidal substances ions that are present in 
the aqueous media pulp suspensions and seems to have a considerable impact on the additive performance in suspension. Furthermore, water system closure in paper mills, especially for paper recycling plants, has increased the importance of conductivity consideration. Different solutions have been considered for controlling the negative effects of high conductivity of pulp suspension on the performance of chemical additives. White water treatments physically (for example with clarifiers using different technique such as integrated membrane process, pulsed electrocoagulation technology, ...) and chemically (with applying different chemicals such as coagulants for water treatment) are the main ones (Hubbe 2000; Bourassa et al. 2003; Perng et al. 2009; Zhang, et al. 2009). Moreover, applying the upgraded wet end additives with improved performance in complicated pulp suspension (such as closed water system in paper recycling mills) can be another solution for facing the mentioned challenge (Hubbe 2000; Wang and Hubbe 2002; Bourassa et al. 2003; Zhang et al. 2009).

Recently, chitosan biopolymers in conjunction with bentonite micro-particles have been considered as a proper applied system for virgin pulp (Rahmaninia et al. 2018). However, its application in recycled old corrugated container (OCC) pulp (a common category of wastepaper containing a variety of dissolved and colloidal contaminants, with high ranges of electrical conductivity) for improving the process and enhancement of the product properties is interesting. Chitosan, which is a derivative of the deacetylation of chitin biopolymers, is a unique environmentally friendly biopolymer with a high positive charge density. It is nontoxic, bio-compatible, antibacterial, and antifungal. These attributes have provided this abundant biopolymer with bright prospects for future applications. Chitosan, which has a $\left(\mathrm{C}_{6} \mathrm{H}_{11} \mathrm{NO}_{4}\right)$ n formula and $\alpha(1 \rightarrow 4)$-linked 2-amino-2deoxy-3-D-glucose bonds, has high compatibility with cellulose (Rohi et al. 2016).

Moreover, bentonite is a sheet-silicate structure montmorillonite clay with threelayers consisting of two tetrahedral layers sandwiched around a central octahedral layer. It has good water absorption abilities. Especially in the case of sodium montmorillonite, it can absorb up to 10 times its dried weight and can swell to 18 times its dried volume. Very tiny particles of bentonite, following dispersion and swelling in water, delaminate and produce a high surface area and charge. The theoretical specific surface area of the montmorillonite may reach to $800 \mathrm{~m}^{2} / \mathrm{g}$. This leads to a very high surface charge of approximately $0.2 \mathrm{C} / \mathrm{m}^{2}$, compared to a cellulosic surface charge of approximately 0.015 $\mathrm{C} / \mathrm{m}^{2}$ (Dehn and McNutt 2015).

In this study, the performance of the chitosan-bentonite micro-particle system in recycled OCC pulp under different electrical conductivities was considered. The high conductivity of pulp suspension in recycled OCC pulp can affect the performance of the wet end ionic additives. It seems that chitosan, with its inherent characteristics, i.e., existence of multiple amino groups on at least $70 \%$ of its chain monomers and therefore high cationic charge through these protonated amino groups, can preserve its electrostatic bonding ability with fibers and fiber fines. Moreover, other probable kinds of bonding, i.e., hydrogen, covalent, and ionic bonding, which may be formed during the system application in pulp suspension, increase the interest in this investigation.

Taheri et al. (2022). "Conductivity \& chitosan-bentonite," BioResources 17(1), 1805-1817. 1806 


\section{EXPERIMENTAL}

\section{Materials}

Old, corrugated containers were randomly selected and collected locally. In addition, the chitosan biopolymer with average molecular weight of 400 to $600 \mathrm{kDa}$ was purchased from Sigma-Aldrich (Steinheim, Germany). This material was a yellow powder with a deacetylated degree of $75 \%$ to $85 \%$. The chitosan aqueous solution was prepared by dissolution in $1 \%(\mathrm{w} / \mathrm{w})$ acetic acid with a final viscosity of approximately $200 \mathrm{cP} . \mathrm{s}$ (at a temperature of $\left.24^{\circ} \mathrm{C}\right)$. White bentonite micro-particles (-1500 mesh screen) were provided by Shimie Sabz Shargh Co. (Mashhad, Iran). The bentonite suspension was prepared with a $0.5 \%(\mathrm{w} / \mathrm{w})$ consistency via agitation in distilled water for $2 \mathrm{~h}$ at room temperature. In addition, calcium chloride $\left(\mathrm{CaCl}_{2}\right)$ was purchased from Merck Co. (Darmstadt, Germany) and used for adjusting the electrical conductivity.

\section{Characterization of Bentonite via Atomic Force Microscopy (AFM)}

An atomic force microscope (Easyscan 2 Flex, Nanosurf, Liestal, Switzerland) was used for the determination of the size dimensions and distribution of the bentonite microparticles.

Moreover, considering the shape of the bentonite particles, a field emission scanning electron microscope (FESEM) image was taken using a Mira3 XMU FE-SEM apparatus (TESCAN, Brno, Czech Republic), at an accelerating voltage of $10 \mathrm{kV}$, at various magnifications.

\section{Chitosan Zeta Potential and the Hydrodynamic Radius}

The zeta potential and the hydrodynamic radius (RH) of the chitosan solution (in $1 \%$ acetic acid) were determined via the dynamic light scattering method (DLS). In this regard, a Nano Zetasizer (Malvern, UK) was used.

\section{Chitosan and Micro-Bentonite Probable Interaction in Suspension via Fourier-Transform Infrared Spectroscopy (FTIR)}

The chitosan and micro-bentonite probable interaction were considered using a Shimadzu FT-IR 8400s spectrometer (Kyoto, Japan). For this purpose, $0.5 \mathrm{~g}$ of a chitosan solution prepared in $1 \%$ acid acetic (with a $0.5 \%$ concentration) was mixed with $0.5 \mathrm{~g}$ of bentonite (with a $0.5 \%$ concentration). The mixture provided alkaline ( $\mathrm{pH}$ of approximately 9) conditions.

\section{Preparation of the Pulp Suspension}

For OCC pulp preparation, the moisture content of the OCC was initially estimated (approximately 8.5\%). Disintegrating and refining were performed with a Valley beater according to TAPPI standard T200 sp-01 (2001). For this purpose, the necessary weight, equal to $360 \mathrm{~g}$ of oven dried OCC pulp, was soaked with a certain amount of deionized water $(20 \mu \mathrm{s} / \mathrm{cm})$ for $24 \mathrm{~h}$, and after slushing, transferred to the beater. The final volume of the pulp suspension in the beater was approximately $23 \mathrm{~L}$; therefore, the final recycled pulp consistency was approximately $1.5 \%$. Disintegrating was performed for 30 min (without the weight applied to the rotor), and then refining was performed until the desired Freeness degree was achieved (350 $\mathrm{mL}$ CSF). Finally, the obtained suspension was kept in a container at a temperature of $5{ }^{\circ} \mathrm{C}$. 


\section{Application of the Chemicals}

The consistency of the pulp suspension before the addition of additives was approximately $0.5 \%$. The $\mathrm{pH}$ of the suspension was adjusted approximately 9 with sodium hydroxide. In addition, the electrical conductivity, as the primary variable in this investigation, was considered at three levels 700,2500 , and $5000 \mu \mathrm{S} / \mathrm{cm}$ with an addition of $\mathrm{CaCl}_{2}$ to the pulp suspension. Chitosan with a $1 \%$ w/w (based on the oven dried pulp) dosage was added to the pulp at a $1000 \mathrm{rpm}$ agitation speed with a $45 \mathrm{sec}$ mixing time. Then, bentonite micro-particles were continuously added to the suspension at $0.1 \% \mathrm{w} / \mathrm{w}$ (based on the oven dried pulp) and at $800 \mathrm{rpm}$ agitation speed for $15 \mathrm{sec}$. Furthermore, the control sample was defined as the pulp suspension without any additives and with an electrical conductivity of about $400 \mu \mathrm{S} / \mathrm{cm}$.

\section{Drainage of Pulp}

The Pulp freeness and drainage measurement was performed according to TAPPI standard T227 om-04 (2004) with a Canadian standard freeness (CSF) tester apparatus (Lorentzen \& Wettre Co., Stockholm, Sweden).

\section{Fines Content and Fines Retention}

The pulp fines content and first pass retention were measured according to TAPPI standard T261 cm-00 (2000), using a dynamic drainage jar (Paper Research Materials (PRM), Inc., Seattle, WA).

\section{Handsheet Making and Mechanical Strengths}

Handsheets with a $130 \mathrm{~g} / \mathrm{m}^{2}$ grammage were made according to TAPPI standard T205 sp-02 (2002). For each treatment, 10 sheets were prepared with a mold handsheet maker and were kept under standard conditions for future experiments. The tensile index (TAPPI standard T494 om-01 (2001)), tear index (TAPPI standard T414 om-04 (2004)), burst index (TAPPI standard T403 om-02 (2002)), and internal bonding strength (TAPPI standard T569 pm-00 (2000)) were evaluated (Sabazoodkhiz et al. 2017).

\section{RESULTS AND DISCUSSION}

\section{Characterization of the Bentonite Micro-Particles via Field Emission Scanning Electron Microscopy (FE-SEM)}

For visualizing the bentonite micro particles, FE-SEM images were prepared. Figure 1 demonstrates the plate-like particles of bentonite with micron dimensions.

Fig. 1. A FE-SEM image of micro-bentonite particles

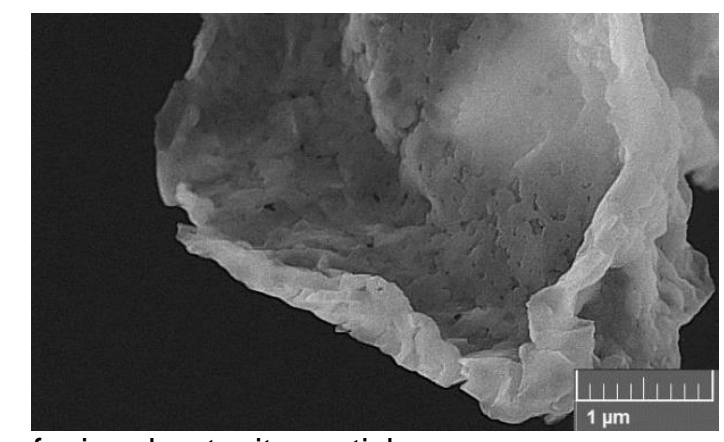

Taheri et al. (2022). "Conductivity \& chitosan-bentonite," BioResources 17(1), 1805-1817. 1808 


\section{Atomic Force Microscopy}

To observe the bentonite particles size topography and distribution, AFM was used. As shown in Fig. 2, despite the micron size of the particle plates, their thickness values ranged from $1 \mathrm{~nm}$ to $22.6 \mathrm{~nm}$, and the maximum frequency of the particle size distribution was approximately $7 \mathrm{~nm}$ to $10 \mathrm{~nm}$.
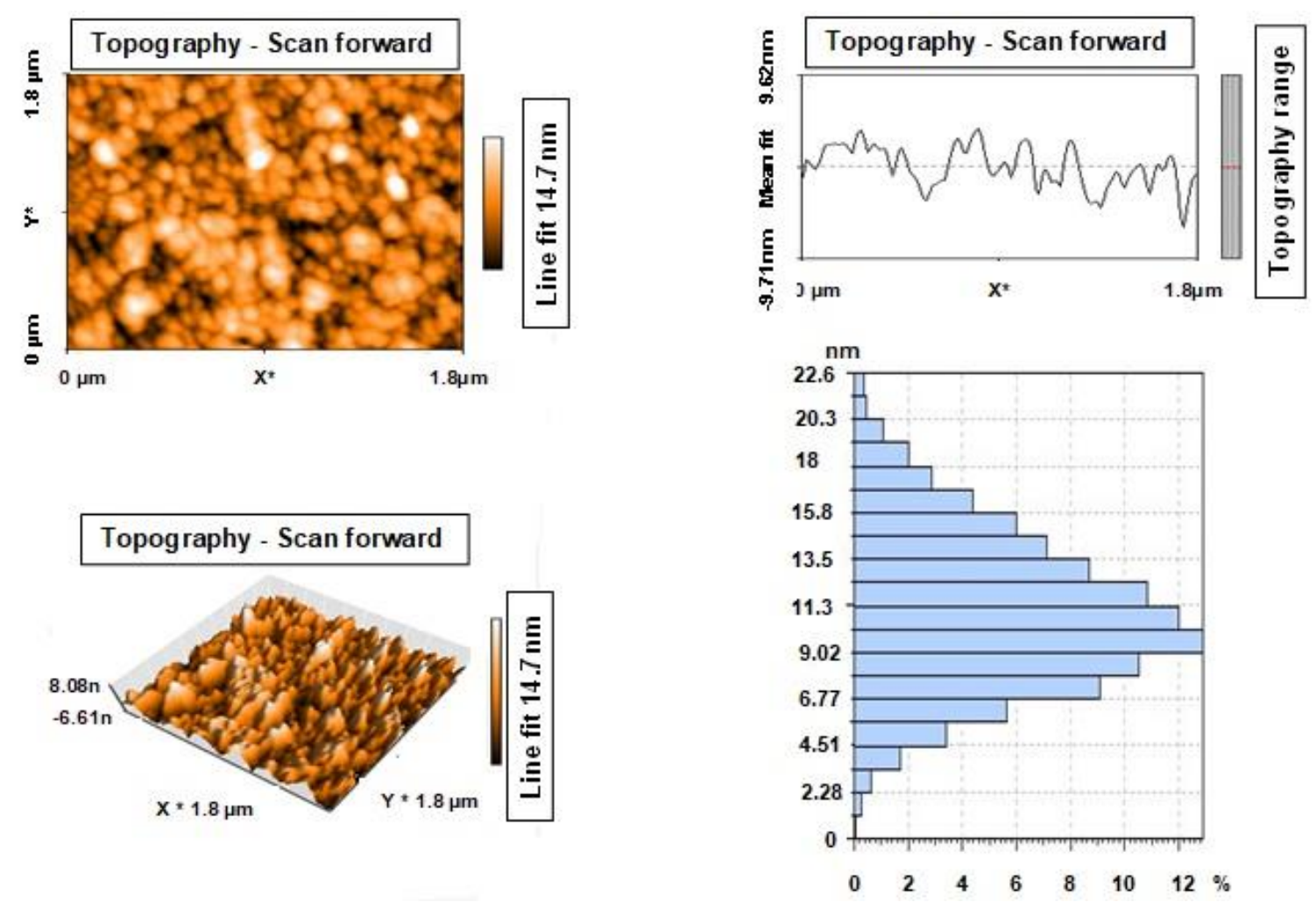

Fig. 2. The AFM images and distribution of the bentonite particles dimensions

\section{Zeta Potential and the Hydrodynamic Radius (HR) of the Chitosan}

The chitosan dimensions after being dissolved in acetic acid (acidic $\mathrm{pH}$ ), as well as its zeta potential, were measured via the DLS method. The results showed that the ionic charge of chitosan was positive and equal to $1220 \mathrm{mV}$ at a $2.3 \mathrm{mS}$ electrical conductivity, with a viscosity of 1.22 cPs. Moreover, the hydrodynamic radius of this polymer was estimated as $2036 \mathrm{~nm}$.

\section{Drainage and Fines Retention of the Recycled Pulp}

The drainage of the water from pulp colloidal suspension is one of the important process parameters. Higher drainability of pulp on the wire of a paper machine before the press and drying section will lead to more productivity and even lower energy consumption. Moreover, the fiber fines/filler retention is also an important criterion in the paper production process. Although in high basis weight papers, the physical retention of small particles in the fibrous structure of the paper is a natural phenomenon, fines retention occurring via retention aid additives, which can affect the retention and even formation efficiency, can be important. 
Figure 3 shows the effect of the electrical conductivity on the drainage and retention of the pulp suspension. As it can be observed in Fig. 3, as the pulp suspension conductivity increased, both the drainage and fines retention decreased. The negative effect of a higher ionic strength on the interaction and adsorption of cationic polyelectrolytes with cellulosic fibers was reported by other researchers (Björklund and Wågberg 1995; Wang and Hubbe 2002; Hubbe et al. 2007; Ryu 2009; Zakrajsek 2014). Lower adsorption, as well as the configuration of the adsorbed polyelectrolyte, certainly deteriorated the performance of the chitosan-bentonite micro-particle system (Hubbe et al. 2007).

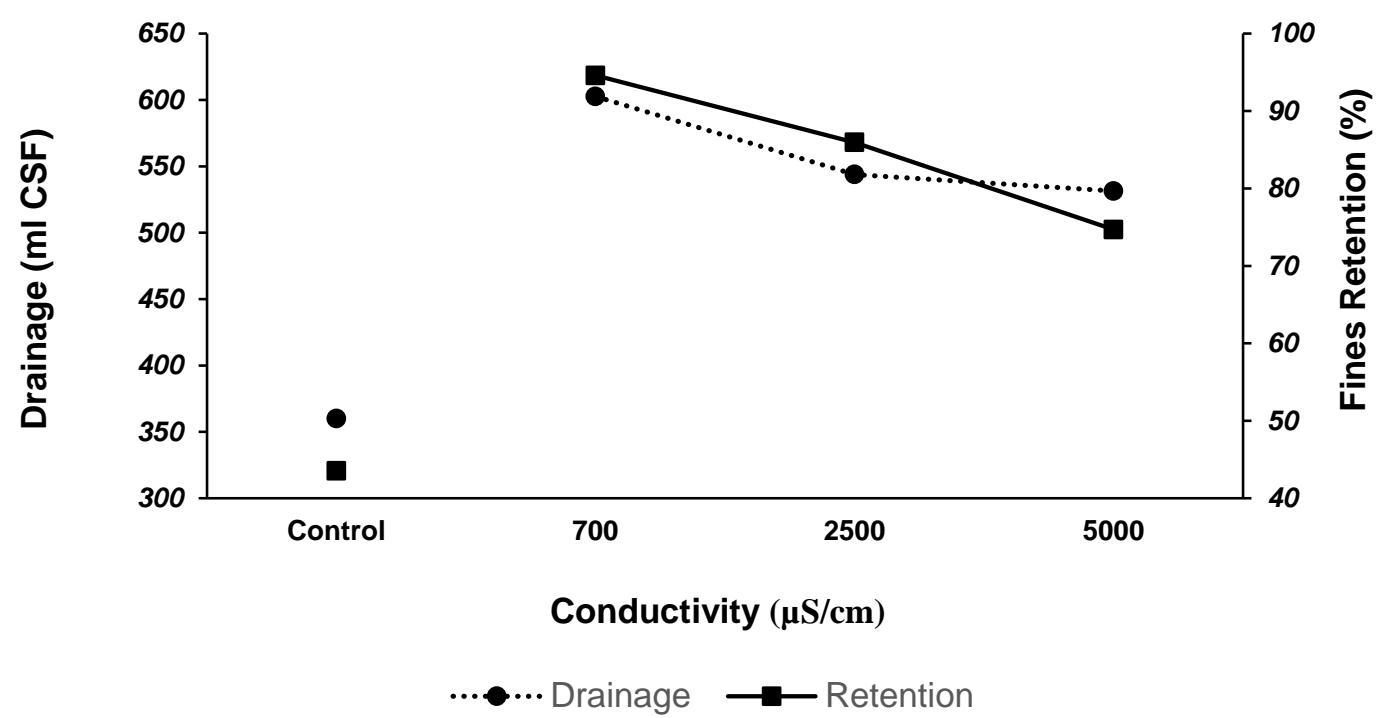

Fig. 3. Effect of the electrical conductivity on the drainage and fines retention (Note: the control is pulp without any additives)

In this respect, what happens in the colloidal suspension can be explained as follows. Although the addition of salts (up to approximately 1 molar) can push the double layer to become thinner with a higher affinity for adsorbing materials with an opposite charge on the negatively charged surfaces of the fibers/fines, higher ion strengths may compete with the cationic polyelectrolyte in terms of adsorption on the surface of the fibers/fines. Moreover, this phenomenon can affect the chitosan configuration from a relatively straight polymer to a coiled one, which may decrease the bridging potential of the chitosan biopolymer with fibers and fiber fines. However, some investigations simulating the mentioned phenomena using silica wafers and quartz showed contrary results (Rojas et al. 1998; Sennerfors et al. 2002; Solberg and Wågberg 2003).

However, an interesting point to mention as an important achievement is the positive performance of the applied micro-particle system in the pulp suspension with high conductivity (up to $5000 \mu \mathrm{s} / \mathrm{cm}$ ). In fact, most of common cationic polyelectrolytes, e.g., cationic starch, and cationic polyacrylamide, etc., lose their efficiency when subjected to high conductivity (Björklund and Wågberg 1995; Wang and Hubbe 2002; Hubbe et al. 2007; Ryu 2009; Zakrajsek 2014). The primary point is the successful performance of the system in an alkaline suspension. Although the positive charge of the amino groups in the chitosan decreased in an alkaline $\mathrm{pH}$, due to the presence of a high numbers of amino groups in the chitosan molecule structure (a degree of deacetylation of approximately $75 \%$ to $85 \%$ ), the positive charge density will remain high even at a higher $\mathrm{pH}$ in comparison with other similar cationic polymers. This high cationic charge probably causes proper 
chitosan configuration with a less coiled shape in suspension, which results in more bridges between the fibers/fines and the chitosan biopolymer. In addition, the high charge density of this cationic biopolymer helps it to compete with other ions present in suspension in terms of adsorption on the fibers/fines.

\section{Tensile and Tear Indices of the Final Paper Sheets}

Tensile strength is an important mechanical property in papermaking. It is affected by different factors, e.g., quantity and quality of bonding (especially the fiber/fiber and fiber/fine bonds). Similarly, the tear strength is a critical property for most paper applications and is related to the fiber length, inherent fiber strength, and bonding quality among the fibers (Kermanian et al. 2013). If the average fiber length and inherent fiber strength are assumed to be constant, then the role of the fibers and fines bonding will be the determining parameter.

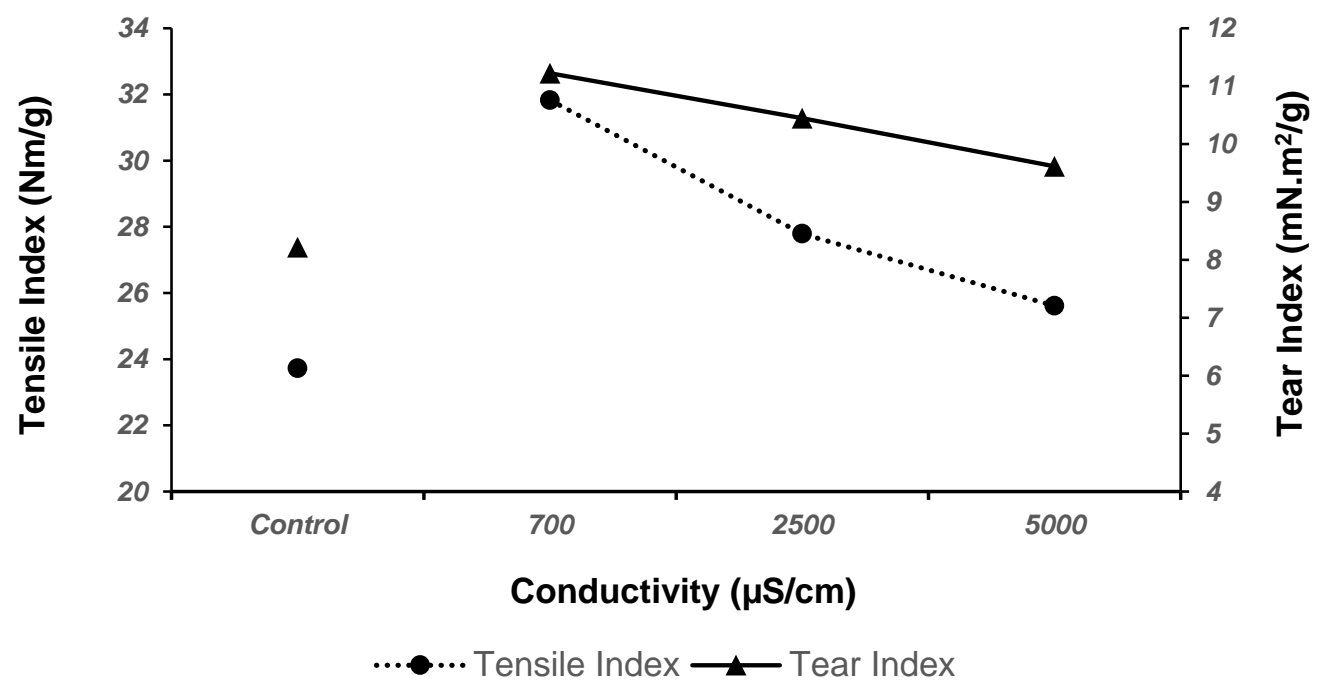

Fig. 4. Effect of the electrical conductivity on the tensile and tear indices of the produced papers (Note: the control is pulp without any additives)

Figure 4 shows the performance of the chitosan-bentonite system in terms of the tensile and tear indices of the prepared sheets from pulp suspensions with different conductivities. Based on these results, all treated specimens with a micro-particle system had better tensile and tear indices in comparison with the control sample. The best results were achieved with a lowest electrical conductivity. In this respect, the additives were primarily responsible for these results. Although the addition of cationic polyelectrolytes can negatively change the fiber mat formation with fiber flocculation phenomenon (Hubbe 2006), it seems that the presence of anionic microparticles in conjunction with a cationic polyelectrolyte can result in an increase in the tensile and tear strengths (Rahmaninia et al. 2018). The mentioned system can increase the bonding between the surfaces of the fibers/fibers and fibers/fines. In this regard, chitosan (a unique biopolymer with a structure similar to cellulose containing a lot of hydroxyl and amine groups) has the proper ability to adsorb on the surface of the fibers/fines and form bridges for developing the bonded area in the final product. In addition, the plate-like anionic microparticles can increase bonding by increasing the number of bridges between the cationic biopolymer chains, which are 
connected and adsorbed on the surface of the fibers/fines. The interaction of chitosan and bentonite micro-particles has been well defined by Rahmaninia et al. (2018).

Moreover, as it can be observed, in the case of both the tear and tensile strengths, by increasing the electrical conductivity, the strengths will decrease. Other investigations support these results (Hubbe and Wang 2002; Hubbe et al. 2007; Ryu 2009; Zakrajsek et al. 2014). It seems that with increasing the electrical conductivity in the colloidal suspension, the polyelectrolyte adsorption on the surface of the fibers will decrease, which probably is due to the reduction in its ability to compete with other positive ions as well as changing the polyelectrolyte to a coil configuration in the aqueous media (Andersson and Sandström 1996).

However, the important point is that the applied system could preserve its performance even at the highest conductivity. This is likely because chitosan, which has a higher positive charge density compared to other cationic additives, can preserve its ability to compete with other positive ions for adsorption on fibers/fines as well as showing a higher resistance in terms of changing to a coil configuration in the pulp suspension.

\section{Internal bond (Scott type) and bending strength index of the produced papers}

Figure 5 shows the performance of the chitosan-bentonite system in terms of two important strengths, i.e., the internal bond strength and bending strength, in paper made from recycled OCC pulp with different conductivities. The internal bond is a property that can show the quality of bonding in a paper structure in the thickness direction of paper (perpendicular to the sheet). This property can be evaluated by several direct and indirect methods. The Scott bond is an indirect method that usually presents logical results with proper anticipation of the paper's internal bonding (Fellers et al. 2012). Generally, the more bonding in the thickness direction, the higher the internal bond strength in the Z-direction. Therefore, any process that can develop the number of bonds between the fibers, or can improve the bonding quality, has a positive effect on this strength. In addition, the bending strength or bending stiffness, which is a function of Young's modulus (elasticity modulus) and a third power of the sheet thickness, is an important index for the final application of paper sheets, especially in terms of carton conversion, printing machine runnability, printing paper cutting, etc. (Ek et al. 2009).

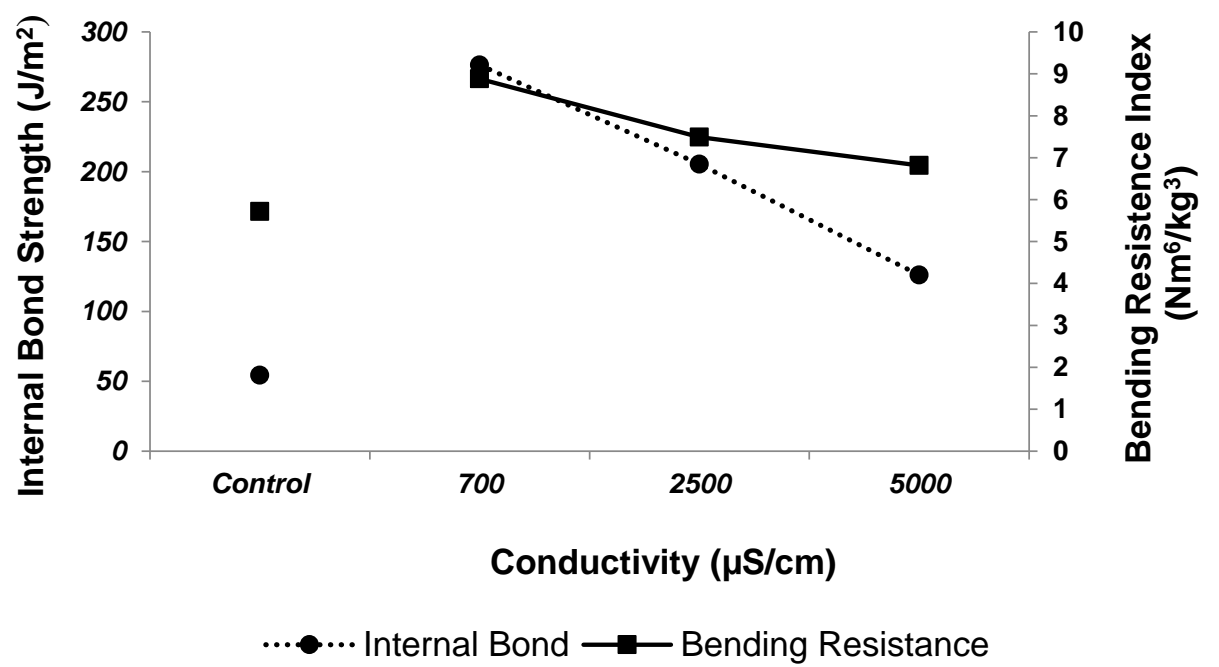

Fig. 5. Effect of the electrical conductivity on the internal bonding strength and bending resistance index of the paper (Note: the control is pulp without any additives)

Taheri et al. (2022). "Conductivity \& chitosan-bentonite," BioResources 17(1), 1805-1817. 1812 
According to Fig. 5, for both internal bonding and resistance to bending, the application of chitosan with bentonite as the micro-particle system in colloidal suspensions with different conductivities resulted in an increase in both compared to the control treatment. It seems that chitosan as a cationic polyelectrolyte with active functional groups (hydroxyl and amino groups) has increased chemical bonding by making bridges among the fibrous materials. The treatment appears also to increase the physical entanglement of the solid parts, especially the fibers and fines, by producing denser flocs by applying bentonite. Furthermore, increasing the colloidal suspension conductivity decreased both mentioned properties. The probable reasons for this could be the decrease in the chitosan adsorption on the pulp components, especially the fibers/fines. Such a decrease could be the result of losing the competition to pulp positive ions as well as the shrinkage in the chitosan structure in aqueous media, which would reduce its bond ability (Andersson et al. 1996; Ryu 2009). However, considering the control samples, the system had preserved its performance even in the highest electrical conductivity equal to $5000 \mu \mathrm{s} / \mathrm{cm}$. As mentioned in previous sections, the inherent high charge density characteristics of chitosan would help it act more properly in the pulp suspensions with complicated aqueous media. Consequently, the chitosan still is able to adsorb onto pulp components and it has more resistance in front of improper configuration.

Moreover, as the bending strength can be directly affected by the thickness, the applied additives, which certainly increase the thickness of paper sheets, can have a positive impact on this property compared to the control samples.

\section{Fourier-transform Infrared Spectroscopy of Chitosan-Bentonite Interaction}

Considering the importance of the probable interaction of chitosan with bentonite in the pulp suspension, the FTIR analysis was applied to chitosan, bentonite, and a chitosan-bentonite mixture (as shown in Fig. 6). The results of the chitosan and bentonite analysis are shown in Table 1. The FTIR results of the chitosan-bentonite mixture showed a slight change and reduction in the wavenumber related to the protonated $\mathrm{N}-\mathrm{H}$ groups, which may be due to the interaction between these protonated groups with the $\mathrm{SiO}$ - groups in bentonite. Moreover, the sharpness of the hydroxyl peak of chitosan at $3435 \mathrm{~cm}^{-1}$ decreased after mixing the chitosan with bentonite, which may be related to hydrogen bonding between these two components (Devi and Dutta 2017; Da Silva et al. 2021).

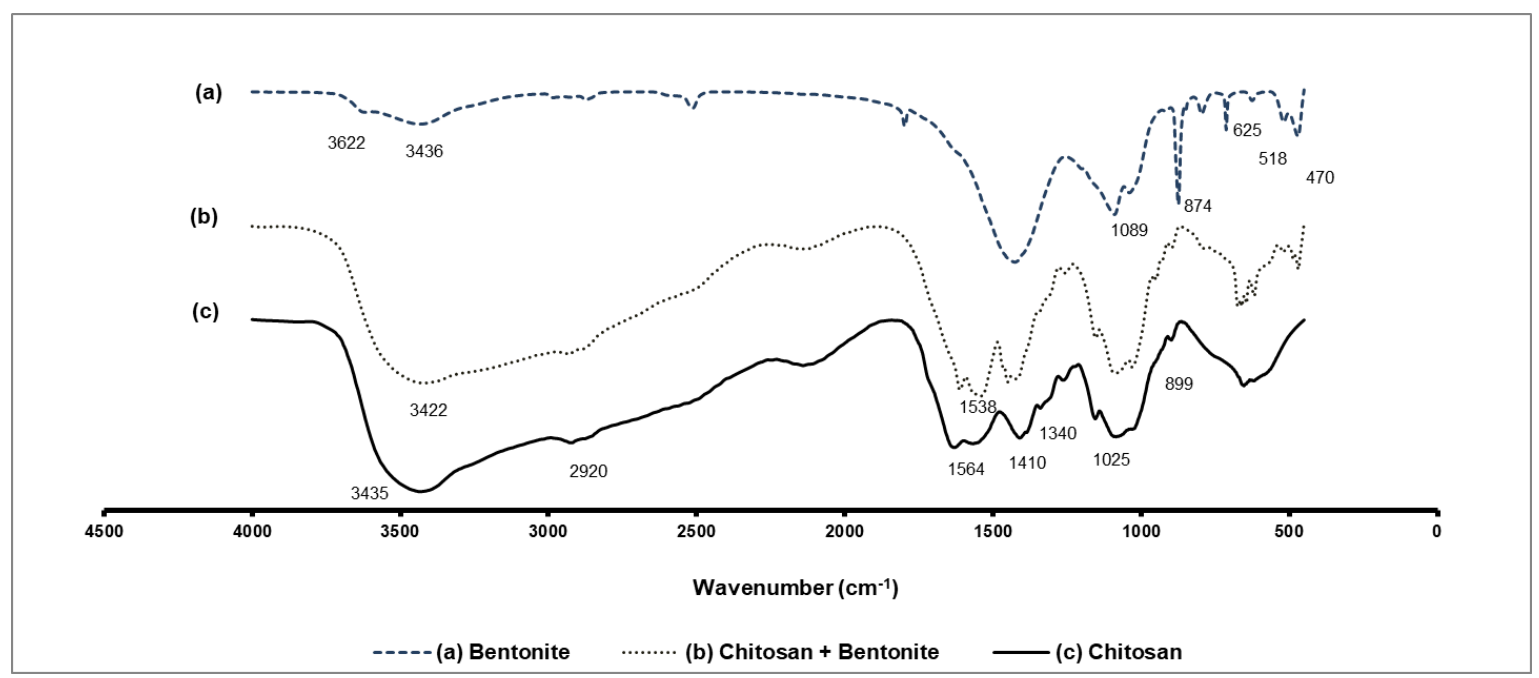

Fig. 6. FTIR analysis of the chitosan-bentonite probable interaction

Taheri et al. (2022). "Conductivity \& chitosan-bentonite," BioResources 17(1), 1805-1817. 1813 
Table 1. Fourier-Transform Infrared (FTIR) Analysis of Bentonite and Chitosan

\begin{tabular}{|c|c|c|c|}
\hline Component & $\begin{array}{l}\text { IR Band } \\
\left(\mathrm{cm}^{-1}\right)\end{array}$ & Description & References \\
\hline \multirow{8}{*}{ Chitosan } & 3435 & $\begin{array}{c}\text { Stretching vibration of hydroxyl groups } \\
\text { overlapped with the Stretching vibration of } \\
\text { amine group N-H }\end{array}$ & $\begin{array}{l}\text { (Sabazoodkhiz et al. } \\
\text { 2017) }\end{array}$ \\
\hline & 2920 & $\mathrm{C}-\mathrm{H}$ Stretching vibration & (Silva et al. 2012) \\
\hline & 1564 & vibrations of protonated $\mathrm{N}-\mathrm{H}$ groups & $\begin{array}{l}\text { (Niroomand et al. } \\
\text { 2016; Sabazoodkhiz } \\
\text { et al. 2017) }\end{array}$ \\
\hline & 1410 & Bending vibrations of $\mathrm{C}-\mathrm{H}_{3}$ groups & $\begin{array}{l}\text { (Mano et al. 2003; } \\
\text { Silva et al. 2012) }\end{array}$ \\
\hline & 1340 & Bending vibrations of methylene groups & (Silva et al. 2012) \\
\hline & 1115 & $\begin{array}{l}\text { C-O-C stretching of the glycosidic linkage } \\
\text { between chitosan monomers }\end{array}$ & $\begin{array}{l}\text { (Niroomand et al. } \\
\text { 2016; Sabazoodkhiz } \\
\text { et al. 2017) }\end{array}$ \\
\hline & 1084 & $\begin{array}{c}\text { Attributed to the vibration of } \mathrm{CO} \text { in } \mathrm{COH}, \mathrm{COC} \\
\text { and } \mathrm{CH}_{2} \mathrm{OH} \text { of the ring }\end{array}$ & $\begin{array}{c}\text { (Silva et al. 2012; } \\
\text { Niroomand et al. } \\
\text { 2016) }\end{array}$ \\
\hline & 899 & wagging of the saccharide structure of chitosan & (Silva et al. 2012) \\
\hline & 3622 & $\begin{array}{l}\text { stretching vibration of hydroxyl groups in } \mathrm{AlOH} \\
\text { and } \mathrm{SiOH}\end{array}$ & $\begin{array}{l}\text { (Sabazoodkhiz et al. } \\
\text { 2017) }\end{array}$ \\
\hline \multirow{4}{*}{ Bentonite } & 3437 & silanol $-\mathrm{OH}$ groups and absorbed water & $\begin{array}{l}\text { (Musić et al. 2011; } \\
\text { Sabazoodkhiz et al. } \\
\text { 2017) }\end{array}$ \\
\hline & $\begin{array}{l}1039 \text { to } \\
1089\end{array}$ & $\begin{array}{l}\text { presence of Silaoxane }(\mathrm{Si}-\mathrm{O}-\mathrm{Si}) \text { stretching } \\
\text { vibration }\end{array}$ & $\begin{array}{l}\text { (Musić et al. 2011; } \\
\text { Yazdimamaghani et } \\
\text { al. 2013) }\end{array}$ \\
\hline & 874 & Bending vibration of $\mathrm{AlFeOH}$ & (Carlson et al. 2007) \\
\hline & 471 & Si-O out of plane (O-Si-O) bending vibrations & $\begin{array}{l}\text { Yazdimamaghani et } \\
\text { al. 2013) }\end{array}$ \\
\hline
\end{tabular}

\section{CONCLUSIONS}

1. The obtained results showed the successful performance of the chitosan-bentonite system for improving the process properties, i.e., fines retention and drainage, and mechanical properties, i.e., tensile and tear indices, internal bond strength, and bending resistance index, in recycled old corrugated container (OCC) pulps.

2. Although increasing the conductivity is a critical and determinative factor in the performance of wet end additives in mills with a closed water loop, the suggested system could successfully diminish this concern.

3. The high charge density of chitosan seems to be the primary reason for its proper performance in the pulp suspension with high conductivity, by maintaining its molecular configuration and creating more bridges with the fibers/fines. In addition, the high charge density of this cationic biopolymer helps it to compete with other ions present in the suspension for adsorption on the fibers/fines. 


\section{ACKNOWLEDGMENTS}

The authors are grateful to Dr. Omid Ramezani, Dr. Hossein Kermanian, and

Engineer Zahra Razmpour for laboratory support at Shahid Beheshti University.

\section{REFERENCES CITED}

Andersson, K., and Sandström, A. (1986). "The use of cationic starch and colloidal silica to improve the drainage characteristics of kraft pulps," Nordic Pulp \& Paper

Research Journal 1(2), 26-30. DOI: 10.3183/npprj-1986-01-02-p026-030

Arminen, H., Hujala, M., Puumalainen, K., Tuppura, A., and Toppinen, A. (2013). “An update on inter-country differences in recovery and utilization of recycled paper," Resources, Conservation and Recycling 78, 124-135. DOI:

10.1016/j.resconrec.2013.07.008

Björklund, M., and Wågberg, L. (1995). "Flocculation of cellulosic fibres following addition of cationic starch," Colloids and Surfaces A: Physicochemical and Engineering Aspects 105(2-3), 199-209. DOI: 10.1016/0927-7757(95)03310-6

Bourassa, C., Diamond, M., Sain, M. and Daneult, C. (2003). "Mill system closure and trash catching porous fillers in papermaking," TAPPI Journal 2(2), 14-18. DOI: 10.1016/j.ijbiomac.2017.02.080

Carlson, L., Karnland, O., Oversby, V. M., Rance, A. P., Smart, N. R., Snellman, M., Vähänen, M., and Werme, L. O. (2007). "Experimental studies of the interactions between anaerobically corroding iron and bentonite," Physical and Chemistry of the Earth, Parts A/B/C 32(1-7), 334-345. DOI: 10.1016/j.pce.2005.12.009

Dehn, J., and McNutt, S. R. (2015). "Volcanic materials in commerce and industry," in: The Encyclopedia of Volcanoes, H. Sigurdsson (ed.), Elsevier, Amsterdam, Netherlands, pp. 1285-1294.

Da Silva, J. C., França, D. B., Rodrigues, F., Oliveira, D. M., Trigueiro, P., Silva Filho, E. C., and Fonseca, M. G. (2021). "What happens when chitosan meets bentonite under microwave-assisted conditions? Clay-based hybrid nanocomposites for dye adsorption," Colloids and Surfaces A: Physicochemical and Engineering Aspects 609, 125584.

Devi, N., and Dutta, J. (2017). "Preparation and characterization of chitosan-bentonite nanocomposite films for wound healing application," International Journal of Biological Macromolecules 104, 1897-1904. DOI: 10.1016/j.ijbiomac.2017.02.080

Ek, M., Gellerstedt, G., and Henriksson, G. (2009). Paper Products Physics and Technology, De Gruyter, Berlin, Germany.

Fellers, C., Östlund, S., and Mäkelä, P. (2012). "Evaluation of the Scott bond test method," Nordic Pulp \& Paper Research Journal 27(2), 231-236. DOI: 10.3183/npprj-2012-27-02-p231-236

Hubbe, M. (2000). "Selecting and interpreting colloidal charge measurements," in: Proceedings of Scientific \& Technical Advances in Wet End Chemistry, Pira International Conference, Barcelona, Spain.

Hubbe, M. A. (2006). "Bonding between cellulosic fibers in the absence and presence of dry-strength agents - A review," BioResources 1(2), 281-318. DOI:

10.15376/biores.1.2.281-318

Hubbe, M. A., Rojas, O. J., Lee, S. Y., Park, S., and Wang, Y. (2007). “Distinctive

Taheri et al. (2022). "Conductivity \& chitosan-bentonite," BioResources 17(1), 1805-1817. 1815 
electrokinetic behavior of nanoporous silica particles treated with cationic polyelectrolyte," Colloid and Surfaces A: Physicochemical and Engineering Aspects 292(2-3), 271-278. DOI: 10.1016/j.colsurfa.2006.06.034

Kermanian, H., Razmpour, Z., Ramezani, O., Mahdavi, S., Rahmaninia, M., and Ashtari, H. (2013). "The influence of refining history of waste NSSC paper on its recyclability," BioResources 8(4), 5424-5434. DOI: 10.15376/biores.8.4.5424-5434

Lindqvist, H. (2013). Improvement of Wet and Dry Web Properties in Papermaking by Controlling Water and Fiber Quality, Ph.D. Dissertation, Abo Akademi University, Turku, Finland.

Mano, J. F., Koniarova, D., and Reis, R. L. (2003). "Thermal properties of thermoplastic starch/synthetic polymer blends with potential biomedical applicability," Journal of Materials Science: Materials in Medicine 14(2), 127-135. DOI: 10.1023/A:1022015712170

Musić, S., Filipović-Vinceković, N., and Sekovanić, L. (2011). "Precipitation of amorphous $\mathrm{SiO}_{2}$ particles and their properties," Brazilian Journal of Chemical Engineering 28(1), 89-94. DOI: 10.1590/S0104-66322011000100011

Niroomand, F., Khosravani, A., and Younesi, H. (2016). "Fabrication and properties of cellulose-nanochitosan biocomposite film using ionic liquid," Cellulose 23, 13111324. DOI: $10.1007 / \mathrm{s} 10570-016-0872-7$

Ordóñez, R., Hermosilla, D., de la Fuente, E., and Blanco, Á. (2009). "Influence of water quality on the efficiency of retention aids systems for the paper industry," Industrial \& Engineering Chemistry Research 48(23), 10247-10252. DOI: 10.1021/ie9010029

Perng, Y.-S., Wang, I.-C., Yu, S.-T., and Chang, A.-Y. (2009). "Application of a pilotscale pulsed electrocoagulation system to OCC-based paper mill effluent," TAPPI Journal 8(3), 14-20.

Perng, Y.-S., Wang, E. I.-C., Chang, C.-K., and Chang, C.-P. (2013). "Nanosericite as an innovative microparticle in dual-chemical paper retention systems," Advances in Materials Science and Engineering 78(35), 456-472. DOI: 10.1155/2013/536961

Pruszynski, P., and Jakubowski, R. (2002). "Impact of conductivity and cationic demand on drainage of TMP-based newsprint furnish," in: Proceedings of the $56^{\text {th }}$ APPITA Conference, 18-20 March, Rotorua, New Zealand, pp. 323-331.

Rahmaninia, M., and Khosravani, A. (2015). "Improving the paper recycling process of old corrugated container wastes," Cellulose Chemistry and Technology 49(2), 203208.

Rahmaninia, M., Rohi, M., Hubbe, M. A., Zabihzadeh, S. M., and Ramezani, O. (2018). "The performance of chitosan with bentonite microparticles as wet-end additive system for paper reinforcement," Carbohydrate Polymers 179, 328-332. DOI: 10.1016/j.carbpol.2017.09.036

Rohi, M., Ramezani, O., Rahmaninia, M., Zabihzadeh, S. M., and Hubbe, M. A. (2016). "Influence of pulp suspension $\mathrm{pH}$ on the performance of chitosan as a strength agent for hardwood CMP paper," Cellulose Chemistry and Technology 50(7-8), 873-878.

Rojas, O. J., Claesson, P. M., Muller, D., and Neuman, R. D. (1998). "The effect of salt concentration on adsorption of low-charge-density polyelectrolytes and interactions between polyelectrolyte-coated surfaces," Journal of Colloid and Interface Science 205(1), 77-88. DOI: 10.1006/jcis.1998.5596

Ryu, J. (2009). Investigation of the Effect of Electrochemical Properties of Multilayered Fibers on the Sheet Properties and the Phenomenon of Adsorption of Polyelectrolytes onto Pulp Fiber in LbL (Layer-by-Layer) Multilayering, Master's Thesis, Seoul 
National University, Korea.

Sabazoodkhiz, R., Rahmaninia, M., and Ramezani, O. (2017). "Interaction of chitosan biopolymer with silica nanoparticles as a novel retention/drainage and reinforcement aid in recycled cellulosic fibers," Cellulose 24, 3433-3444. DOI: 10.1007/s10570017-1345-3

Sennerfors, T, Solberg D, and Tiberg F (2002). "Adsorption of polyelectrolytenanoparticle systems on silica: Influence of ionic strength," Journal of Colloid and Interface Science 254(2), 222-226. DOI: 10.1006/jcis.2002.8582

Silva, S. M. L., Braga, C. R. C., Fook, M. V. L., Raposo, C. M. O., Carvalho, L. H., and Canedo, E. L. (2012). "Application of infrared spectroscopy to analysis of chitosan/clay nanocomposites," in: Infrared Spectroscopy-Materials Science, Engineering and Technology, T. Theophile (ed.), InTech, London, pp. 43-62.

Solberg, D., and Wågberg, L. (2003). "Adsorption and flocculation behavior of cationic polyacrylamide and colloidal silica," Colloids and Surfaces A: Physicochemical and Engineering Aspects 219(1-3), 161-172. DOI: 10.1016/S0927-7757(03)00029-3

TAPPI T200 sp-01 (2001). "Laboratory beating of pulp (Valley beater method)," TAPPI Press, Atlanta, GA.

TAPPI T205 sp-02 (2002). "Forming handsheets for physical tests of pulp," TAPPI Press, Atlanta, GA.

TAPPI T227 om-04 (2004). "Freeness of pulp (Canadian standard method)," TAPPI Press, Atlanta, GA.

TAPPI T261 cm-00 (2000). "Fines fraction by weight of paper stock by wet screening," TAPPI Press, Atlanta, GA.

TAPPI T403 om-02 (2002). "Bursting strength of paper," TAPPI Press, Atlanta, GA.

TAPPI T414 om-04 (2004). "Internal tearing resistance of paper (Elmendorf-type method)," TAPPI Press, Atlanta, GA.

TAPPI T494 om-01 (2001). "Tensile properties of paper and paperboard (using constant rate of elongation apparatus)," TAPPI Press, Atlanta, GA.

TAPPI T569 pm-00 (2000). "Internal bond strength (Scott type)," TAPPI Press, Atlanta, GA.

Wang, F., and Hubbe, M. A. (2002). "Charge properties of fibers in the paper mill environment. 1. Effect of electrical conductivity," Journal of Pulp and Paper Science 28(10), 347-353.

Yazdimamaghani, M., Pourvala, T., Motamedi, E., Fathi, B., Vashaee, D., and Tayebi, L. (2013). "Synthesis and characterization of encapsulated nanosilica particles with an acrylic copolymer by in situ emulsion polymerization using thermo responsive nonionic surfactant," Materials 6(9), 3727-3741. DOI: 10.3390/ma6093727

Zakrajsek, N. (2014). "Influence of inorganic salts on the adsorption of cationically modified starch to fibers," Food and Nutrition Science 5(3), 245-249. DOI: 10.4236/fns.2014.53030

Zhang, Y., Ma, C., Ye, F., Kong, Y., and Li, H. (2009). "The treatment of wastewater of paper mill with integrated membrane process," Desalination 236(1-3), 349-356. DOI: 10.1016/j.desal.2007.10.086

Article submitted: November 18, 2021; Peer review completed: January 1, 2022; Revised version received: January 17, 2022; Accepted: January 20, 2022; Published: January 26, 2022.

DOI: $10.15376 /$ biores.17.1.1805-1817 